\title{
Application of Domino Theory to Justify and Prevent Accident Occurance in Construction Sites
}

\author{
Pejman Ghasemi Poor Sabet ${ }^{1}$, Hamid Aadal ${ }^{2}$, Mir Hadi Moazen jamshidi ${ }^{3}$, \\ Kiyanoosh Golchin $\operatorname{Rad}^{4}$ \\ ${ }^{1,2,4}$ (Department of Structure and Materials, Faculty of Civil Engineering, Universiti Teknologi \\ Malaysia (UTM), Johor Bahru, Johor, Malaysia) \\ ${ }^{3}$ (Department of Management \& Human Resource development, Universiti Teknologi Malaysia, Johor Bahro, \\ Malaysia)
}

\begin{abstract}
: since the construction activities involve most complex processes and the most intensive administrative atmosphere as well, the accident events come raised in different situations and due to various causations. Most of the construction accidents originate from human errors and operation sources such as equipments and facilities in work processes. Most accidents lead to the loss of life, injuries and loss of properties. The other possible results due to the errors, unsafe acts, and unsafe conditions can be categorized in Near miss events (no result of injuries), and incidents (likelihood of injuries or loss of property). The role of a tool by which the causations and the processes can be highlighted is vital to save the projects not to be trapped. In order to recognize the reasons or the factors contributing to accidents, several theories have been developed by researchers. Domino theory as a structural map has been one of the most understandable and widely acceptable theories among the accident theories. The authorities employ it to control the factors causing undesirable events and to prevent the errors before being made. The aims of this paper are firstly, to describe the shortcomings of construction processes contributing hazardous situations. secondly, highlighting, the ways to apply Domino theory, and thirdly, to define how to establish a remedy model to prevent accidents in construction projects based on domino theory in simple statements.
\end{abstract}

Keywords: Application of Domino theory, Construction accidents, Remedy model of Domino theory

\section{Introduction}

Quality, time and money are the vital and the main factors to be controlled with regard to a project's productivity. The focus of attention concerning safety as the issues affecting the main factors has been as a significant function that most problem and operational issues arise on projects[1]. Therefore, preventing and controlling the threatening factors that waste the project's sources are the most significant purposes in keeping a smooth running. The studies done in several countries such as Finland, Turkey, the USA, China, and Korea revealed that construction industry has amounted to a high rate of adverse consequence due to poor $\mathrm{H} \& \mathrm{~S}$ performance [2].According to the statistics, construction industry is the second hazardous job after fishing industry in Europe. The rate of fatal events and casualties amounted to almost 13 persons per 100,000 while, generally, at the other sectors just was announced 5 per 100, 000. The number of fatal construction injuries made the rate of 13.3 per 100,000 employees. Such accidents within construction sites usually come from falls from height, excavation accident, machines, electrocution, being struck by falling objects, and vehicle crash[3]. Those accidents can be originated from a worker's simple mistake worker to a professional negligence due to the lack of supervision. The impacts of the mistakes can range from non serious hurts up to severe outcomes. Construction accidents are one of the most common problems which have received authorities' attention to the projects to eliminate or to mitigate the results of the accidents. Such accidents cause the conditions to lead to downtime and expanses due to remedy and compensation as well.

Although Mechanization could have been combined with industries, construction industry is still being involved in high accident rate compared to the other working environments [4].Many scholars have categorized same factors to create construction accidents so that many approaches and theories have been developed with different forms but with similar meaning to handle and manage the situations leading to accidents. Domino theory focuses on developing an understandable theory which can define and justify the accident factors. It also emphasizes the processes contributing to accident occurrence within the construction at all levels of employees from general workers up to engineers and managers. 


\section{Heinrich Domino Theory}

In 1929, Herbert William Heinrich developed a theory called Domino theory. The theory has been expanded many times during several years. The steps of accident causations labeled on five metaphorical dominos in the sequences are showed below:

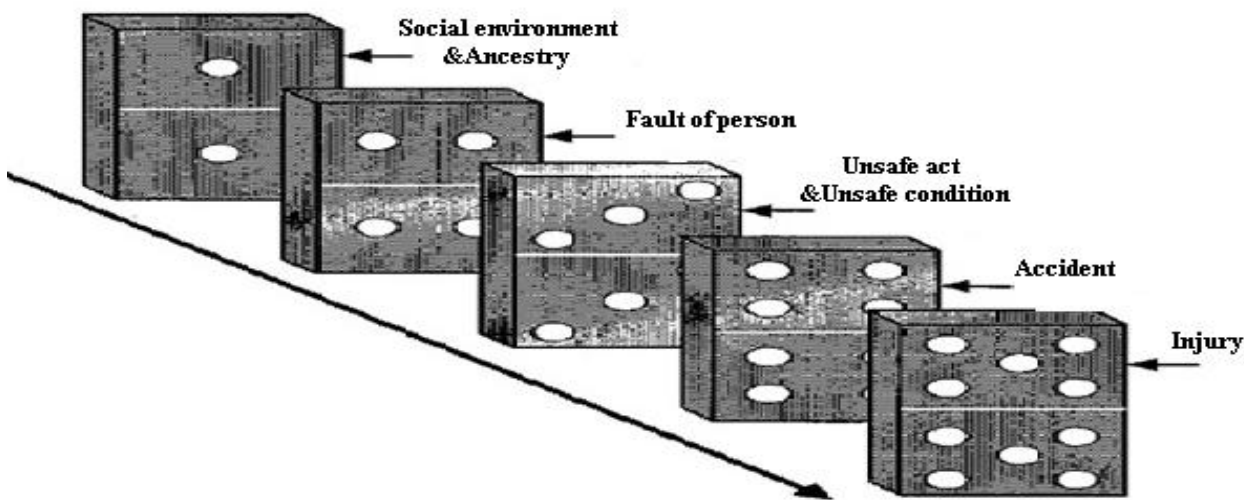

Figure2. Heinriech's Domino's sequences of accident causation theory

- Social Environment and Ancestry:

Some characteristics such as recklessness, greed, and bad temper are originated from either inheritance or social environment. In other words, such traits can be raised nature and nurture contributing to fault of person.

- Fault of Person:

Some unpleasant manners or traits such as ignorance, recklessness, and bad temper can be innate. Also, such traits can appear due to life environments contributing to unsafe Acts or unsafe conditions.

- Unsafe Acts or Unsafe Conditions:

Unsafe acts and unsafe conditions are labeled on the domino at the center of sequences contributing to an accident. They are the most significant factor to cause an accident. Lifting up this domino is the easiest and the most efficient option in order to prevent an accident.

- Accident:

The accidents are the undesirable and the unwanted events that happen and cause injury. The events can be such as a person's fall from height and striking a person due to collapse of objects.

- Injury:

Injuries are the consequences suffering damage to someone's body[5].

\subsection{Weakness Of Heinrich's Domino Theory}

Although Heinrich's Domino theory was one of the most understandable and the clearest theories defining accident processes, it was suffering some weakness affected its application. As a result of the weaknesses, the theory was revised because of emphasizing blame on individuals very much, not considering the fault from management and organization, and the belief about a single cause where there may be more than one.

\section{Accident Causation In Construction Sites}

Construction accidents arise due to seven factors. Such factors include Procedural, Economical, Psychological, Organizational, Environmental, Technical, and Historical factors. This study focused on how these factors play roles in creating accidents. The UK construction industry demonstrated several accident causal factors such as[6]:

- The nature of project

- The method of construction

- Site restriction

- Project duration

- Procurement system

- Design complexity

- Level of construction

- Subcontracting contributing to accident causation

Another study categorized the root causes of construction accidents in the form of a fish bone. The diagram below presents the result of the study [7]. 


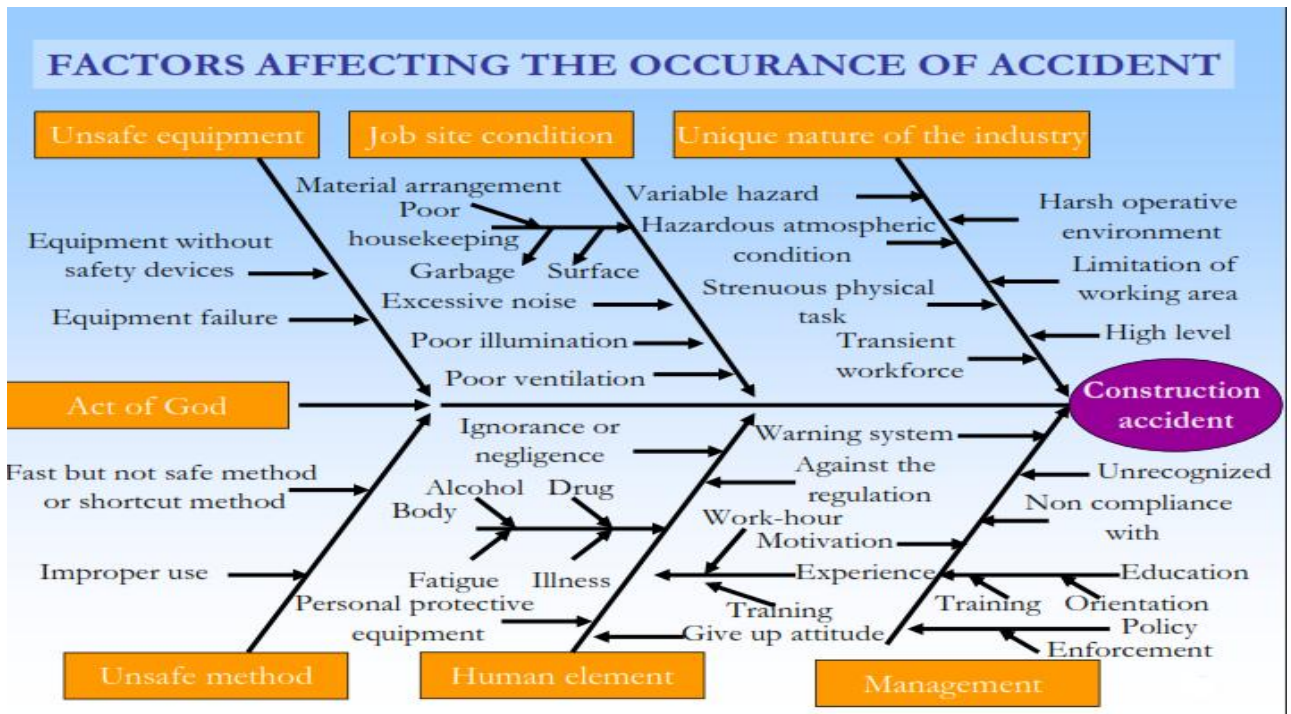

Figure1. Construction Project Features (CPFs)

\section{Updated Domino Theory}

The role of management entered into the "Domino theory" by Bird and Loftus in 1974 and was placed in the sequence of accident causes developed by Heinrich (See Fig.3). As a result, the new sequences included:

1. Lack of control/management

2. Basic causes/origins (basic causes: 1-personnel factors, 2-job factors)

3. Immediate causes/Symptoms (unsafe act and condition)

4. Incident (the events which could cause harm to either people or properties)

5. Loss (properties, people, processes).

According to the revised model of Domino theory that signifies the role of management, the process of incidents begins by the lack of control by management. Planning, controlling, organizing, and leading by management are the factors that can prevent incidents to happen [8].

Basic causes were classified by Vincoly into two various groups:

- Personnel factors: the factors include personal problems (non work-related), mental problems, illness, bad attitude, and lack of understanding or ability.

- Job factors: these factors are such as inadequate work, normal or abnormal wear and tear, low-quality equipment, and bad design or maintenance.

The revised model also defines unsafe acts and conditions as the symptoms of root causes that originated from domino 1 and 2 (shown in Fig.3) while Vincoly believes that the management system allows the factors to be unchecked and uncontrolled so that an incident happens [9].

\section{CLASSIFICATION OF CONSTRUCTION PROJECTS FEATURES (Cpfs) BASED ON THE REVISED DOMINO THEORY}

According to Fig.1 (Fish bone of CPFs) and the revised domino theory, the features such as Act of God, Unsafe method, Job site conditions, and unsafe equipments can be categorized into second domino as the job factors. The management is classified as the underlying cause while immediate causes (Unsafe act/Unsafe condition) are followed the accident steps.

Heinrich states that $\square \square$ each step of accident sequences in domino theory is followed by the next so that, finally lead to an accident. The construction accidents amount to 88 percent by unsafe acts of a person while unsafe conditions make 10 percent of the number of the accidents. Also, Two percent of construction accidents are created due to Act of God. It is noticeable that act of God concept in domino theory implies the fact that there might be a level of risk which is not controllable[8]. 


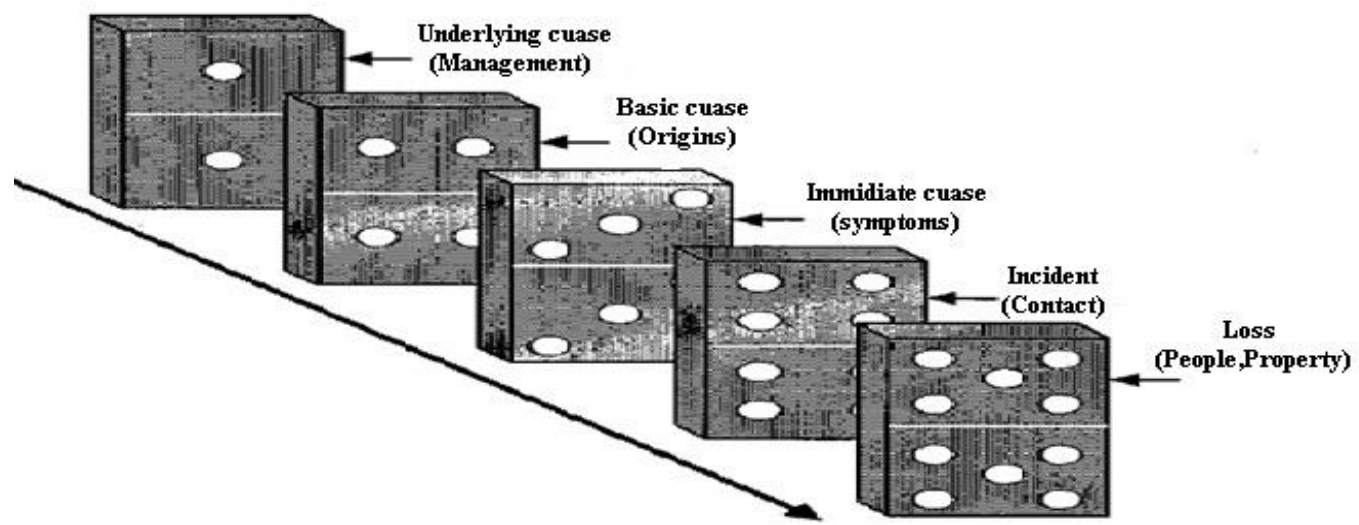

Figure3. Updated Domino sequence of accident causation theory (Bird 1974)

\section{The Persistence Of The Dominoe Theory}

As described by Heinrich in 1929, Domino theory is different from the other accident theories in terms of intelligibility so that it is applicable and employable at all position levels from workers to experts and managers. The distinguishing traits of the theory that make it unique to be employed are:

- Simplicity

The theory describes the steps of causality logically in simple words. Therefore, it is easy to apply it and an investigator does not need to look for many complexes interrelating reasons as well. It is also understandable for those who are not specialists in safety issues.

- $\quad$ Easy fix being

Approximately everybody who involves in a business has experienced the processes of Domino theory. It means that, establishing and conducting the line of the theory easily are possible by all individuals.

- Blame placing

The person who creates harm to others can be easily recognized based on the sequences of the theory. Thus, an appropriate blame can be placed on the right individual in order to compensate the loss or the injury imposed. Hence, the theory is desirable for the people who have lost their rights.

- The way to be looked good and professional

Certainly an investigator would reflect the ability of solving incident. The investigator state that the professionalism of the one is reflected while the one knows how to prevent the incident to be reoccurred[5]:

\section{The Remedy Model Of Domino Theory:}

James Reason believes that there is always a relationship between behaviors and their following outcomes. Organizations have to provide suitable protection for the probable risks come arise from either the unsafe acts or the consequences in terms of the peoples' well-being involved[7]. The level of the protection must be defined logically in such a way that it should not cost more than required and, vice versa, not to be less than associated probable risks to be occurred. To keep the company's profits, to gain opportunities for the company, and to prevent unwanted and undesirable expenses are the main purposes in an organization. Therefore, such purposes can be threatened by unsafe acts and unsafe conditions. Unsafe acts and unsafe conditions as immediate causes play the most significant role in creating losses. The easiest way to remedy the theory is lifting the domino out of the line. Some of the unsafe acts and conditions are insufficient light, absence of rail guards, unguarded point of operation, removal of safeguards and mechanical or physical hazards, horseplay, starting machinery without warning, standing under suspended load[8].

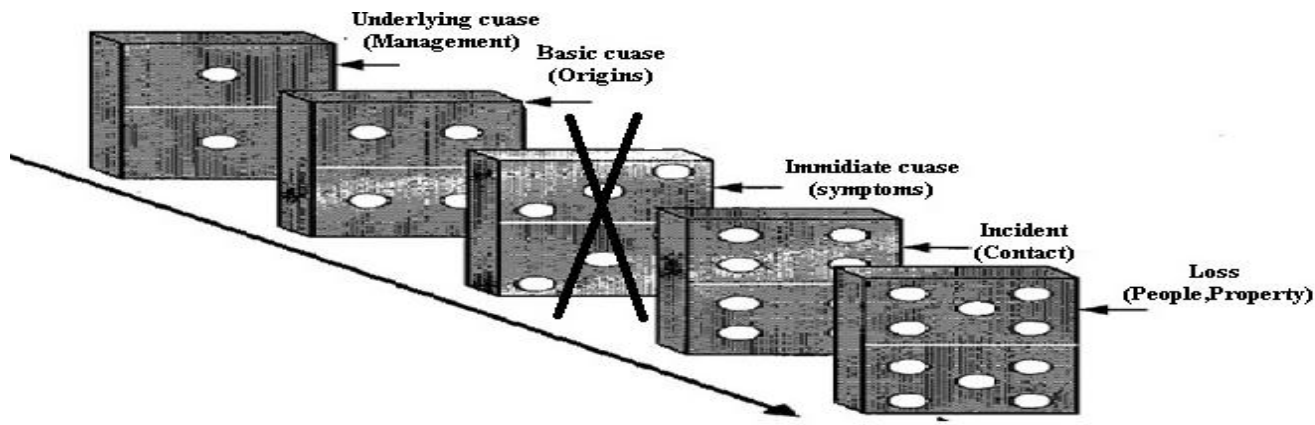

Figure4. Remedy model of Domino theory 


\section{Results And Discussion}

Theories and models of construction accidents are developed based on the description of how construction accidents happen. These immediate and contributing causes of accidents are clarified by the theories. Although, several of the other accident theories represent accident causation perfectly, Domino theory describes a simple model based on a singular concept of risk masterly.

As explained, unsafe acts and unsafe conditions are categorized as immediate causes constituted safety management failures and physical and mental conditions of the employees. The role of humans resulting in accidents at Domino theory is highlighted. Later, Ferrel (1977), Peterson (1982), and Mc Clay (1989) extended the human error idea of accident causation through highlighting the role of human factors in their accident theory. There always exists the possibility of adverse effect due to the interactions between the work environment, the workers, equipments, tools, and the others involved in the activities that establish the sequences of events towards accidents [10]. According to the simplicity of domino theory to make it understandable for all levels of construction personnel, the safety measures can be developed significantly. The safe working environment pushes a project toward fast productivity following the improvement of safety performance.

\section{Conclusion}

Accidents and incidents are the most current troubles that a construction site encounters with. They lead to unwanted expenses and downtime resulting in non-productivity or entrammels. Accidents happen while the employees behave unsafely or offer unsafe acts and the management ignores the presence on unsafe conditions coming arise. Therefore unsafe acts and unsafe conditions as the immediate (direct) causes of accidents are the central factors to cause an accident. Other physical and mental conditions of an employee as well as environmental forces and the lack of supervision on safety performance are the contributory causes of unsafe act and unsafe conditions leading to accidents.

Following such problems that occurred in construction sites, the researchers developed several theories to justify the processes of accidents or incidents and presented the ways to eliminate the causes of losses or injuries. Domino theory as the most understandable and easiest model was developed by Heinrich in 1929. It was revised by Bird and Loftus in 1976 and then by Vincoli in 1994. The structure of the theory consists of five metaphorical dominoes labeled with accident and incident causes listed in sequences shown in Fig.2 and Fig. 3 as the revised model. Underlying causes originated from management while the basic causes are related to job and personnel factors. The remedy model dedicates lifting up the domino3 (Unsafe acts/Unsafe conditions).In other words, eliminating unsafe acts and unsafe condition is the best and the easiest measure to be taken within the steps of accident causations.

\section{References}

[1] Jamshidi, M.H.M., et al., Essential Competencies for the Human Resource Managers and Professionals in Construction Industries. Journal of Basic and Applied Scientific Research, 2012.

[2] Manu, P., et al., An approach for determining the extent of contribution of construction project features to accident causation. Safety Science, 2010. 48(6): p. 687-692.

[3] Viscusi, W.K. and J.E. Aldy, The value of a statistical life: a critical review of market estimates throughout the world. Journal of risk and uncertainty, 2003. 27(1): p. 5-76.

[4] Hosseinian, S.S. and Z.J. Torghabeh, MAJOR THEORIES OF CONSTRUCTION ACCIDENT CAUSATION MODELS: A LITERATURE REVIEW. International Journal, 1963. 4.

[5] Heinrich, H.W., Industrial Accident Prevention. A Scientific Approach. Industrial Accident Prevention. A Scientific Approach., 1941(Second Edition).

[6] Suraji, A., A.R. Duff, and S.J. Peckitt, Development of causal model of construction accident causation. Journal of construction engineering and management, 2001. 127(4): p. 337-344.

[7] Hamid, A., et al., Causes of accidents at construction sites. Malaysian Journal of Civil Engineering, 2008. 20(2): p. $242-259$.

[8] Katsakiori, P., G. Sakellaropoulos, and E. Manatakis, Towards an evaluation of accident investigation methods in terms of their alignment with accident causation models. Safety Science, 2009. 47(7): p. 1007-1015.

[9] Vincoli, J.W., Basic guide to accident investigation and loss control. Vol. 1. 1994: John Wiley \& Sons.

[10] Taylor, G., K. Easter, and R. Hegney, Enhancing occupational safety and health. 2004: Elsevier Butterworth-Heinemann. 